\title{
Investigating the impact of cleaning treatments on polystyrene using SEM, AFM and ToF-SIMS
}

\author{
Anna L. Fricker ${ }^{1,2^{*}}$, David S. McPhail ${ }^{3}$, Brenda Keneghan ${ }^{2}$ and Boris Pretzel ${ }^{2}$
}

\begin{abstract}
Concerns about the stability of plastic artefacts are commonly expressed when discussing the conservation of modern materials. One of the factors affecting the degradation of plastics is the presence of soil, degradation products and other contaminants on the surface. Cleaning treatments for plastic artefacts may therefore increase their stability as well as improving their visual appearance. While past studies have shown that dry, aqueous and solvent cleaning can visibly damage a plastic surface, the chemical and physical changes occurring to the surface at the micro-scale have been largely unexplored. In this work time-of-flight secondary ion mass spectrometry (ToF-SIMS) has been used in conjunction with atomic force microscopy (AFM) and scanning electron microscopy (SEM) to examine the effect of cleaning treatments on the surface of sheet polystyrene. Chemometric analysis of the ToF-SIMS data reveals the presence of surfactant residues and contamination from cleaning agents while physical damage in the form of scratching has been characterised using AFM and SEM. It is anticipated such work will assist in informing future conservation treatments for plastics.
\end{abstract}

Keywords: Cleaning, Plastic, Polymer, Polystyrene, ToF-SIMS, SEM, PCA, AFM, Surfactant, Conservation

\section{Background}

Plastic artefacts are found in many of the world's museums and heritage institutions [1-3]. According to collection surveys performed in the 1990s it is estimated that approximately $75 \%$ of plastics in a museum's collection require cleaning for aesthetic and conservation reasons [4]. Soiling from fingerprints, particulate matter or atmospheric pollutants can compromise the stability of an object, making it more prone to degradation. However, physical contact with the surface via a conservation treatment such as cleaning also has the potential to damage the artefact or to introduce detrimental changes to the surface. This work examines the effect of cleaning on one plastic, polystyrene, due to its presence in the collections of the Victoria and Albert Museum (V\&A) [1].

\footnotetext{
*Correspondence: fricker@gmail.com

1 Department of Materials, Imperial College London, Exhibition Road, London SW7 2AZ, UK

Full list of author information is available at the end of the article
}

An EUFP7-funded project entitled 'Preservation of plastic artefacts in museum collections' (POPART) [5], examined the effect of both dry and wet cleaning treatments on a range of plastics, including high impact polystyrene (HIPS). Findings indicated that cleaning introduces scratches to the surface and in some cases these are accompanied by residue deposition, either from the cleaning agent or the application material $[5,6]$. In particular, the POPART study on HIPS [5] found that a microfibre cloth was the least damaging application method, while a non-ionic surfactant, Dehypon LS45, was found to be the least detrimental surfactant, closely followed by Orvus WA Paste, an anionic surfactant. Organic solvents were also effective, particularly ethanol and 2-propanol, although they introduced scratches to artificially soiled samples.

Previous work also found that cleaning introduces physical damage to the surface of polyvinyl chloride (PVC) [7] as well as introducing residues identified using attenuated total reflectance Fourier transform infra-red (ATR-FTIR) spectroscopy [8]. Examination of post-cleaned surfaces 
has heretofore predominantly been performed using low magnification techniques such as optical microscopy or optical profilometry. Thus it is of interest to examine the surface at a micro- and/or nano-scale to determine whether any other changes are occurring that are not detectable either by the naked eye or light microscopy. Such chemical and physical defects may have long-term implications for the stability of a plastic object.

Advanced analytical techniques can provide valuable information about surface topography and chemical composition. Secondary ion mass spectrometry (SIMS) has been used in conservation research to examine corrosion in metals and glass [9] as well as enabling the identification of polymers [10]. In this work, scanning electron microscopy (SEM) and atomic force microscopy (AFM) were used to examine surface topography while time-offlight secondary ion mass spectrometry (ToF-SIMS) was used to characterise surface chemistry changes. Principal component analysis (PCA) of the ToF-SIMS data was used to characterise variations in surface chemistry due to the cleaning procedures.

\section{Experimental Materials}

Transparent flat polystyrene sheets were sourced from Plastics Direct Ltd. (UK) and were supplied with a protective polymer film. Individual samples measuring $15 \mathrm{~mm} \times 20 \mathrm{~mm} \times 1.8 \mathrm{~mm}$ were cut with the protective film in place; the film was removed prior to the application of cleaning treatments. Cleaning agents and their application method were chosen with reference to prior work [5] which found they caused minimal damage to the polymers investigated. Dry cleaning was performed with a white microfibre cloth ( $80 \%$ polyester, $20 \%$ polyamide) sourced from Conservation by Design (UK) (Product No. SUWMFC7523) and manufactured by Stouls (France). Three aqueous cleaning treatments were also investigated: deionised water, sourced from a Merck Millipore Direct- $\mathrm{Q}^{\circledR}$ water purification system (Merck, Germany) with a resistivity of $18.2 \mathrm{M} \Omega \mathrm{cm}$ at $25^{\circ} \mathrm{C}$; an anionic surfactant (Orvus WA Paste), sourced from Conservation Resources UK (UK) and a non-ionic surfactant (Dehypon LS45), sourced from Restore Products (UK). Both surfactants were diluted to a $1 \%$ concentration with deionised water before application. Two ACS grade organic solvents: ethanol and 2-propanol were also used and were supplied by VWR International (USA). All cleaning agents were applied with a microfibre cloth in a straight line direction, as this had previously be found to be more effective cleaning procedure than a circular motion [5].

Cleaning was achieved by attaching the cloth to a $\mathrm{K}$ control bar coater (RK Print, UK) which was used to draw the cloth once across the surface with a velocity of approximately $2.7 \times 10^{-2} \mathrm{~ms}^{-1}$ and a lateral force of $2.7 \times 10^{-3} \mathrm{~N}$. The bar was supported at either end by grips and fixed at a height of $2 \mathrm{~mm}$ above the surface to limit the downward force exerted on the surface. As the bar was free to move upwards in the vertical direction, the maximum possible downward force over the entire surface due to the mass of the bar was equal to $1 \mathrm{~N}$. This is a rather high pressure and equivalent to rubbing with the thumb. However, given that the thickness of the cloth ranged between approximately $2.5 \mathrm{~mm}$ and $0.8 \mathrm{~mm}$ when fully compressed, it is unlikely that this maximum force was exerted on the surface during cleaning.

Substrates cleaned with surfactants underwent rinsing with deionised water to remove residual surfactant. Rinsing was performed using the same method as cleaning and a new piece of cloth was used for each cleaning or rinsing procedure. The cleaning treatments are summarised in Table 1.

\section{Physical characterisation}

Topographical information was obtained using a Leo Gemini 1525 FEG-SEM (Carl Zeiss AG, Germany), operated in high vacuum at an EHT of $5 \mathrm{kV}$. A secondary electron in-lens detector was used. All samples were sputter coated with approximately a $20 \mathrm{~nm}$ layer of gold before imaging using an Quorum Emitech K550 sputter coater (Quorum Technologies, UK).

A Bruker Innova atomic force microscope (Bruker Corporation, USA) was used in tapping mode to obtain further information about the surface topography. Micrographs were captured at a scan rate of $1 \mathrm{~Hz}$ and at $512 \times 512$ pixel resolution.

\section{Chemical characterisation}

Chemical information about the surface composition was obtained using time-of-flight secondary ion mass spectrometry (ToF-SIMS). The instrument used was a TOF. SIMS 5 (ION-TOF GmbH, Germany) with a $25 \mathrm{keV} \mathrm{Bi}_{3}{ }^{+}$ primary beam, an emission current of $1 \mathrm{nA}$ and a target current of $0.3 \mathrm{pA}$. Spectra were obtained from a $100 \mu \mathrm{m} \times 100 \mu \mathrm{m}$ analysis area over a period of $60 \mathrm{~s}$. At least 8 spectra were obtained for each substrate.

Chemometric data analysis of the ToF-SIMS spectra from the surface was performed via principal component analysis (PCA) using the PLS_Toolbox version 6.2.1 (Eigenvector Research Inc, USA) in MATLAB (The Mathworks Inc, USA). Spectra were Poisson-scaled, sumnormalised and mean-centred prior to analysis.

Depth profiles of the surface and sub-surface region were performed using a $5 \mathrm{keV} \mathrm{Ar}_{1000}{ }^{+}$sputter beam and $25 \mathrm{keV} \mathrm{Bi}_{3}{ }^{+}$primary beam in non-interlaced mode. A $300 \mu \mathrm{m} \times 300 \mu \mathrm{m}$ crater was sputtered and a $100 \mu \mathrm{m} \times 100 \mu \mathrm{m}$ area in the centre of this crater was 
Table 1 Summary of the six cleaning treatments used in this work

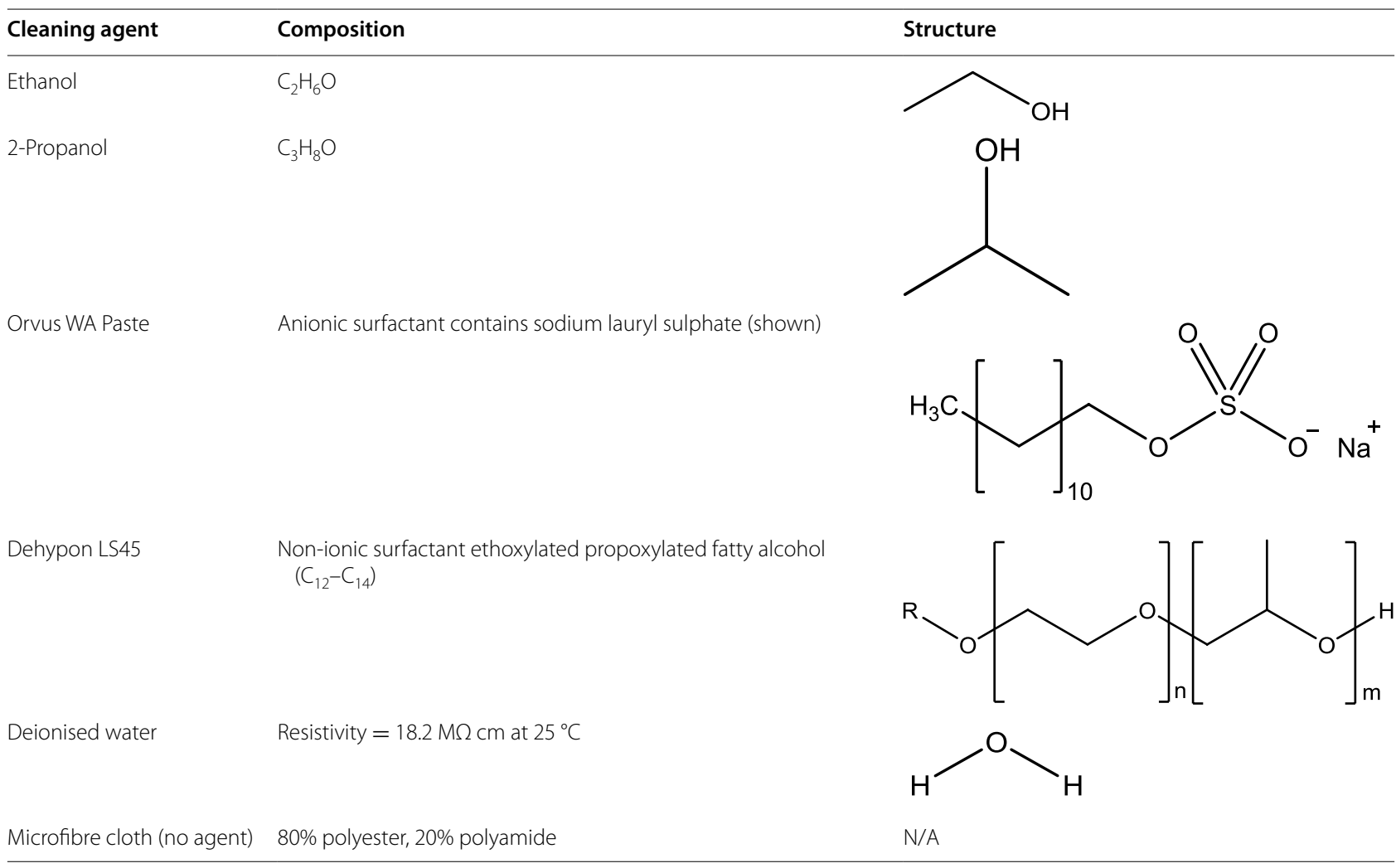

analysed. Calibration of the crater depths was achieved using a Zygo NewView 200 interferometer (Zygo Corporation, USA), assuming a constant sputter rate.

\section{Results}

\section{Initial surface characterisation}

Physical and chemical characterisation of the surface was performed prior to cleaning. Figure 1a shows a positive SIMS spectrum of the untreated polystyrene surface, displaying characteristic peaks at $\mathrm{m} / \mathrm{z}=77.04\left(\mathrm{C}_{6} \mathrm{H}_{5}{ }^{+}\right)$, 91.05 $\left(\mathrm{C}_{7} \mathrm{H}_{7}{ }^{+}\right)$and $117.07\left(\mathrm{C}_{9} \mathrm{H}_{9}{ }^{+}\right)$[11]. A negative SIMS spectrum is shown in Fig. $1 \mathrm{~b}$ and displays peaks at $\mathrm{C}_{\mathrm{n}}^{-}$ and $\mathrm{C}_{\mathrm{n}} \mathrm{H}^{-}$, which are characteristic of hydrocarbon polymers [11].

SEM micrographs of the untreated polystyrene surface are shown in Fig. 2a, b. The untreated substrate does not display the presence of surface imperfections although some particulates are present which have typical diameter of around $10 \mu \mathrm{m}$ and are attributed to dust. The cracking effect on these substrates is due to the gold sputter coating.

\section{Physical changes due to cleaning}

SEM examination of the polystyrene substrates was performed for all treated and untreated samples. Figure 2c shows a micrograph of polystyrene after cleaning with a dry microfibre cloth and reveals a number of microscratches parallel with the cleaning direction, which are not visible to the naked eye. It can be seen there are a number of scratches within approximately a $10 \mu \mathrm{m}^{2}$ area which have a similar topography, although there is some variation in width. Closer inspection of the scratch topography in the rectangular area in Fig. 2c is shown in Fig. 2d. The central trough of the largest scratch is around $200 \mathrm{~nm}$, whilst the width of the entire damaged area is $\sim 500 \mathrm{~nm}$. Scratching was typically observed for all cleaned substrates, irrespective of the cleaning agent used. No scratches were observed on the uncleaned substrate.

AFM micrographs provide further information about the scratch topography of the substrates after cleaning. Figure 3a shows an AFM micrograph of polystyrene cleaned with the dry microfibre cloth. A linear surface profile represented by the white arrow is shown in Fig. $3 \mathrm{~b}$. On average the peak-to-peak width of scratches is $\sim 200 \mathrm{~nm}$, which agrees with the trough width determined by SEM and the maximum peak-to-valley (PV) height is $\sim 20 \mathrm{~nm}$. These scratch magnitudes are typical of those observed after the application of all cleaning treatments. The profile has a lateral resolution of $10 \mathrm{~nm}$ and a vertical resolution of $1 \mathrm{~nm}$. 

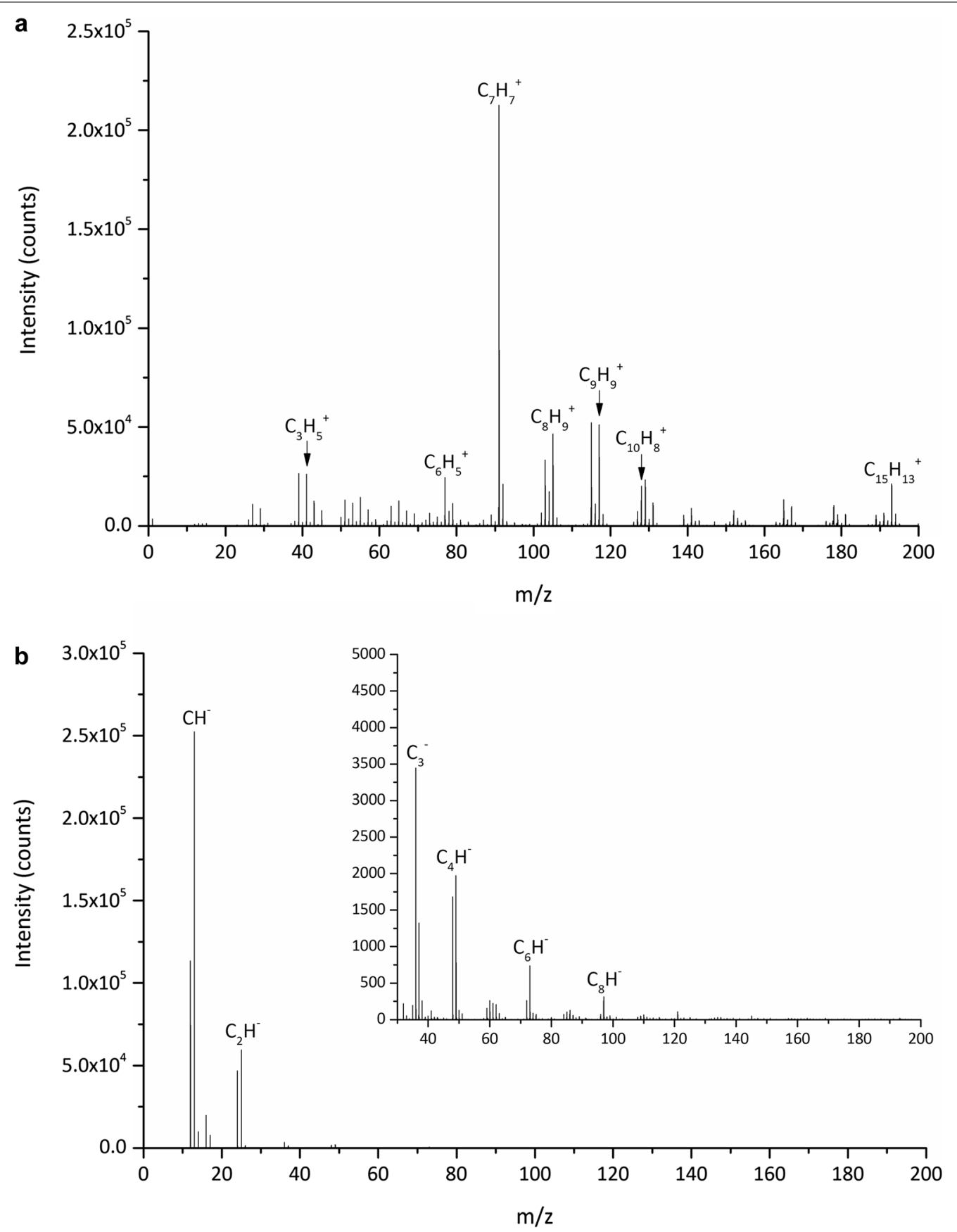

Fig. 1 a Positive ToF-SIMS spectrum and $\mathbf{b}$ negative ToF-SIMS spectrum of the untreated polystyrene $(\mathrm{m} / \mathrm{z}<200)$

\section{SEM analysis of microfibre cloth}

SEM micrographs of the microfibre cloth prior to cleaning demonstrate the presence of small particles on the cloth fibres (Fig. 4) which may be responsible for scratches incurred by the polystyrene substrate and which typically have a diameter of $<200 \mathrm{~nm}$. Alternatively, the scratches may result from small dust particulates present on the polystyrene surface prior to cleaning. It is not thought the scratches are caused by the cloth fibres, due to the irregular nature and width of the scratches $(\sim 200 \mathrm{~nm})$, which are two orders of magnitude lower than the fibre diameter $(\sim 20 \mu \mathrm{m})$. 

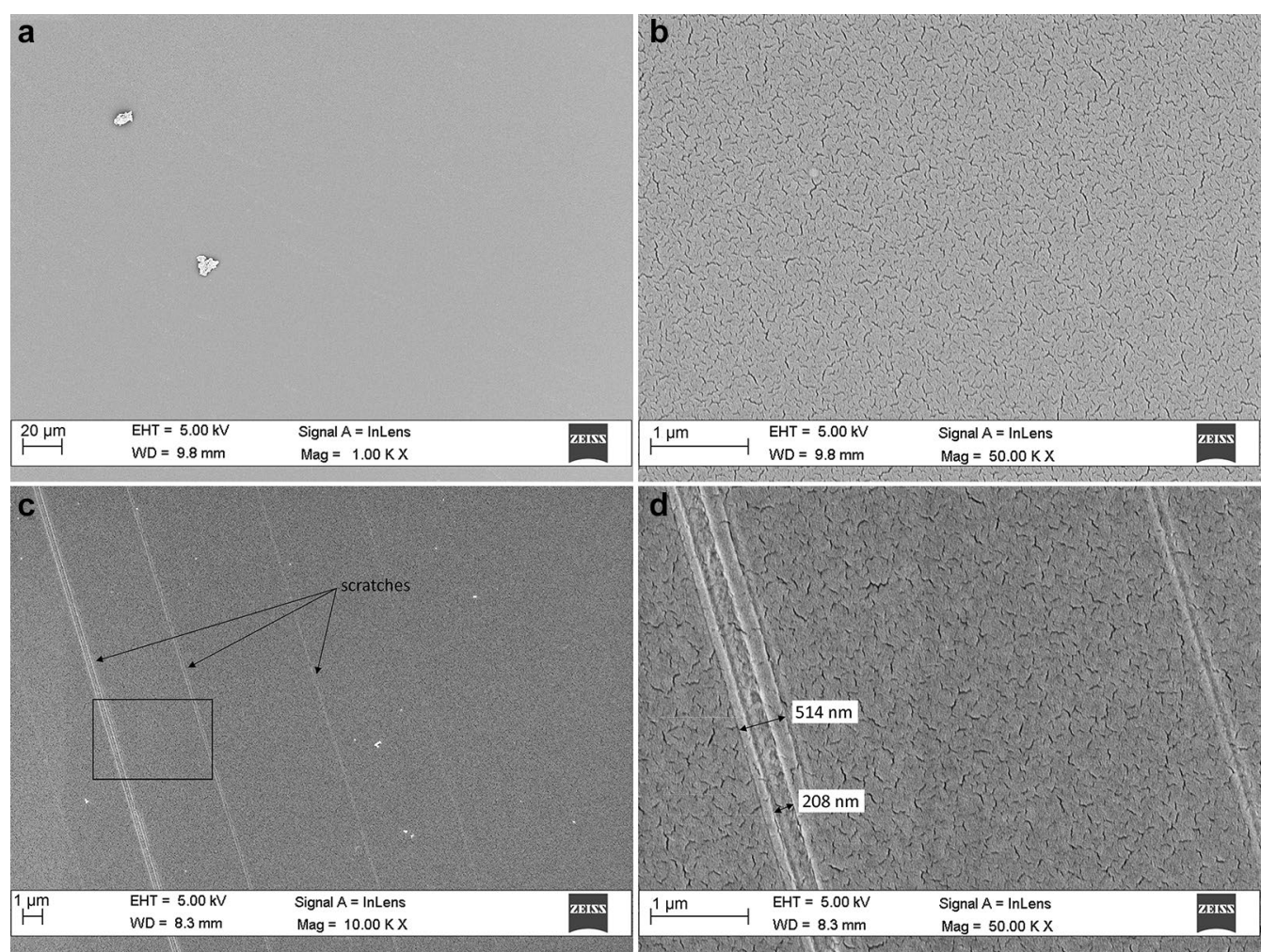

Fig. 2 SEM micrographs of $\mathbf{a}$ and $\mathbf{b}$ the untreated polystyrene surface, $\mathbf{c}$ polystyrene after cleaning with a dry microfibre cloth showing the presence of scratches on the surface and $\mathbf{d}$ close-up of the area indicated by the black rectangle in $\mathbf{c}$
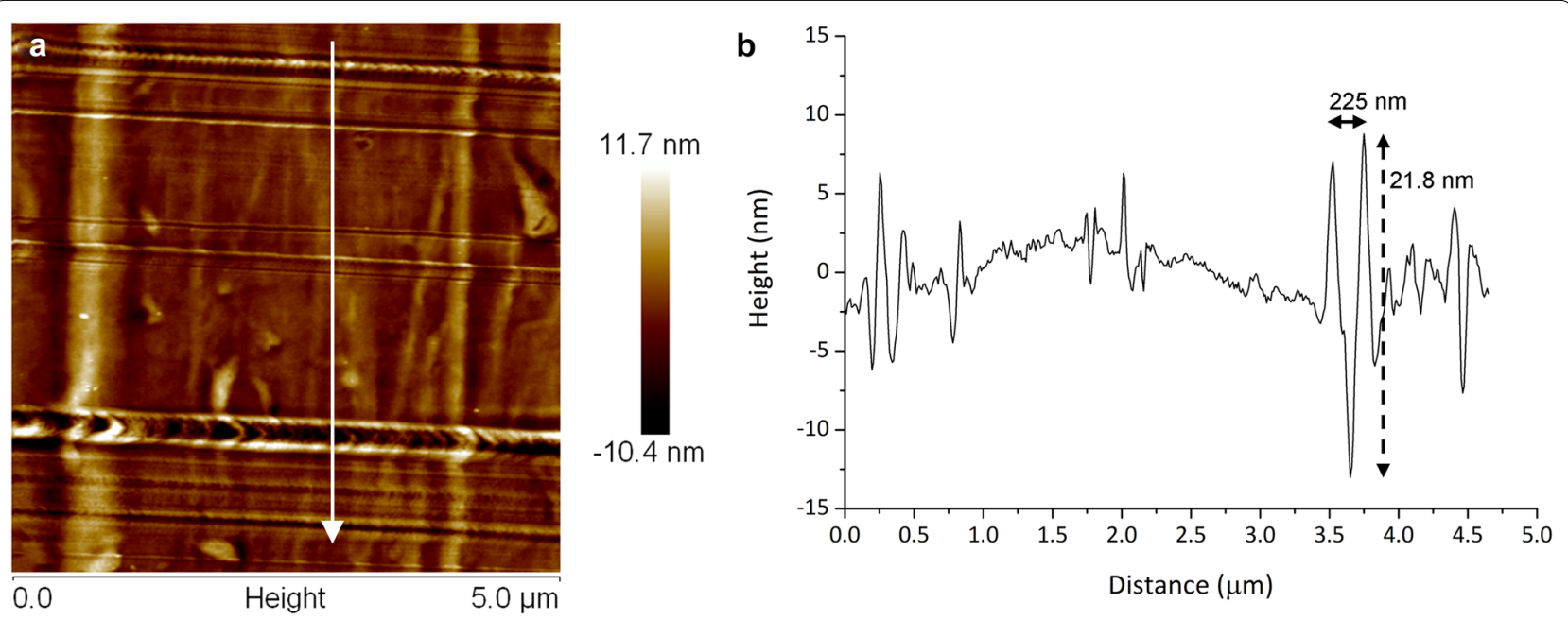

Fig. 3 a AFM micrograph of the polystyrene substrate cleaned with the microfibre cloth and $\mathbf{b}$ the associated line profile along the direction of the white arrow

\section{Changes in surface chemistry due to cleaning}

Cleaning agents, particularly surfactants, might be expected to change the surface chemistry of the polystyrene substrates. ToF-SIMS followed by PCA analysis was therefore used to obtain chemical information about the surface via the molecular fragments identified. Uncleaned polystyrene is characterised in the positive polarity by molecular fragments at $\mathrm{m} / \mathrm{z}=77.04\left(\mathrm{C}_{6} \mathrm{H}_{5}{ }^{+}\right)$, 


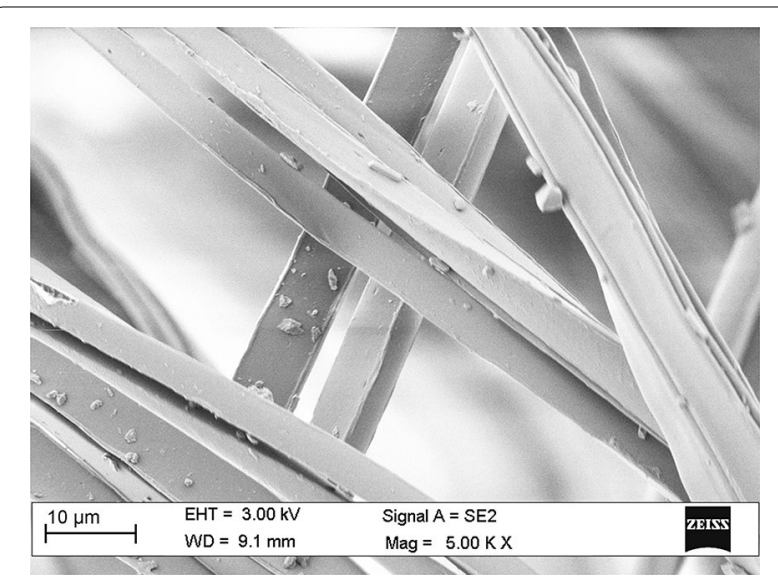

Fig. 4 SEM micrograph of the microfibre cloth fibres prior to cleaning

$91.05\left(\mathrm{C}_{7} \mathrm{H}_{7}{ }^{+}\right)$and $117.07\left(\mathrm{C}_{9} \mathrm{H}_{9}{ }^{+}\right)$(Fig. 1a) while Dehypon LS45 is characterised by molecular fragments at $\mathrm{m} / \mathrm{z}=31.02\left(\mathrm{CH}_{3} \mathrm{O}^{+}\right), 45.03\left(\mathrm{C}_{2} \mathrm{H}_{5} \mathrm{O}^{+}\right)$and 59.05 $\left(\mathrm{C}_{3} \mathrm{H}_{7} \mathrm{O}^{+}\right)$. PCA scores and loadings plots comparing uncleaned polystyrene to polystyrene cleaned with Dehypon LS45 are shown in Fig. 5. Positive loadings on PC1 are consistent with a residue film of the non-ionic surfactant on the polystyrene surface after cleaning.

Similarly, a residue was also detected for the substrates cleaned with the anionic surfactant (Orvus WA Paste), which contains sodium lauryl sulphate (SLS). PCA of the negative polarity ToF-SIMS spectra reveals fragments at $\mathrm{m} / \mathrm{z}=79.96\left(\mathrm{SO}_{3}{ }^{-}\right)$and $96.96\left(\mathrm{SO}_{4} \mathrm{H}^{-}\right)$corresponding to SLS residue on the polystyrene surface (Fig. 6). Positive loadings on PC1 are representative of the uncleaned surface and are comprised of hydrocarbon ions which are characteristic of polystyrene.

In order to determine the effect of rinsing on surfactant residues, PCA analysis was performed on polystyrene cleaned with the anionic surfactant and rinsed one to five times with deionised water. Figure 7 shows the scores and loadings for these substrates; samples that were rinsed one to two times are characterised by fragments at $\mathrm{m} / \mathrm{z}=32.98\left(\mathrm{HS}^{-}\right), 47.97\left(\mathrm{SO}^{-}\right), 63.96\left(\mathrm{SO}_{2}{ }^{-}\right)$, $79.96\left(\mathrm{SO}_{3}{ }^{-}\right), 96.96\left(\mathrm{HSO}_{4}{ }^{-}\right)$and $154.02\left(\mathrm{C}_{4} \mathrm{H}_{9} \mathrm{SO}_{4}{ }^{-}\right)$, corresponding to the anionic SLS surfactant remaining as a surface residue. However, polystyrene samples rinsed three or more times are characterised by fragments at $\mathrm{m} / \mathrm{z}=58.02\left(\mathrm{C}_{2} \mathrm{H}_{6} \mathrm{Si}^{-}\right), 71.03\left(\mathrm{C}_{3} \mathrm{H}_{7} \mathrm{Si}^{-}\right), 89.04$ $\left(\mathrm{C}_{3} \mathrm{H}_{9} \mathrm{OSi}^{-}\right)$and $163.02\left(\mathrm{C}_{4} \mathrm{H}_{11} \mathrm{O}_{3} \mathrm{Si}_{2}{ }^{-}\right)$, attributed to polydimethylsiloxane (PDMS), a common lubricant [12].

The extent of residue from the anionic surfactant on the surface was determined by obtaining depth profiles for fragments at $\mathrm{m} / \mathrm{z}=63.96\left(\mathrm{SO}_{2}{ }^{-}\right), 79.96\left(\mathrm{SO}_{3}{ }^{-}\right)$, $96.96\left(\mathrm{HSO}_{4}{ }^{-}\right)$and $265.16\left(\mathrm{C}_{12} \mathrm{H}_{25} \mathrm{SO}_{4}{ }^{-}\right)$corresponding to SLS, shown in Fig. 8a. It can be seen the intensity of these fragments sharply decrease with depth, and start to flatten out around $30 \mathrm{~nm}$, indicating the presence of residual surfactant on the polystyrene surface after the cleaning and rinsing procedure. The thickness of this layer is consistent with a monolayer or sub-monolayer of surfactant on the surface. Figure $8 \mathrm{~b}$ shows the depth profile of the $\mathrm{SO}_{3}{ }^{-}$fragment for the polystyrene surface after cleaning with the anionic surfactant followed by multiple rinsing steps. These depth profiles indicate a monolayer of surfactant remains on the surface even after repeated rinsing.
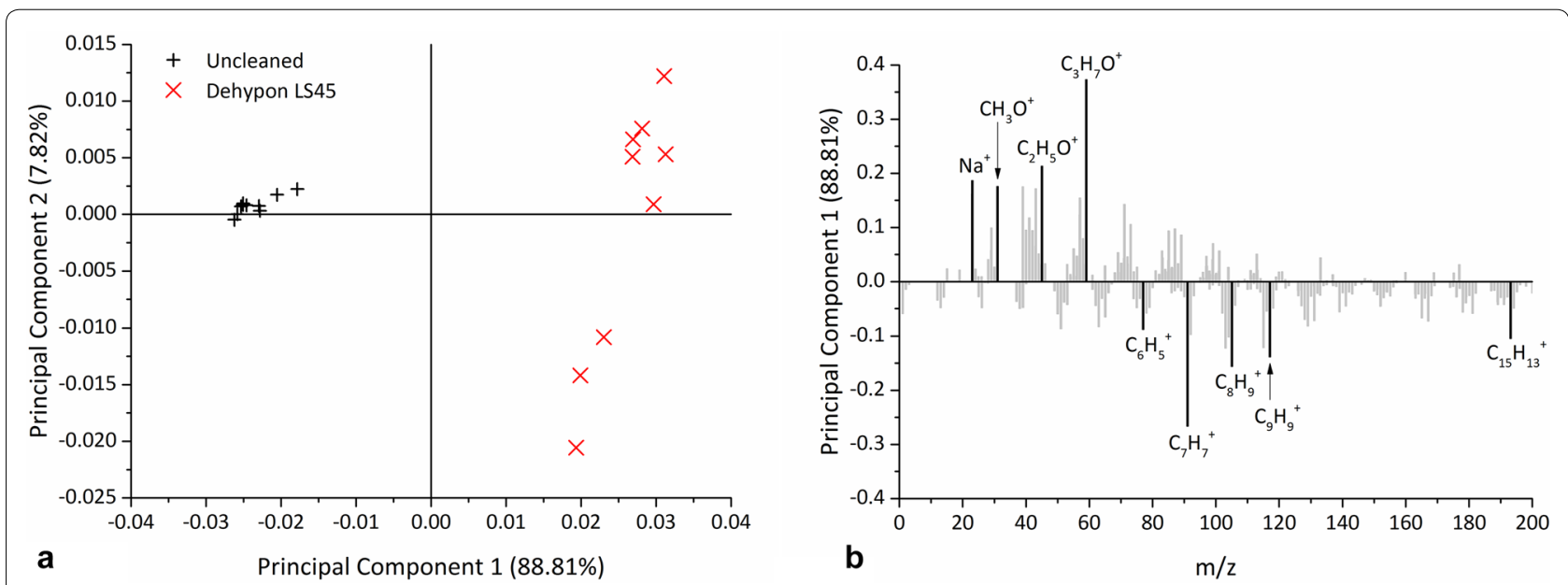

Fig. 5 PCA a scores and $\mathbf{b}$ loadings plots for the positive polarity ToF-SIMS spectra from the substrates cleaned with the non-ionic surfactant (Dehypon LS45) 

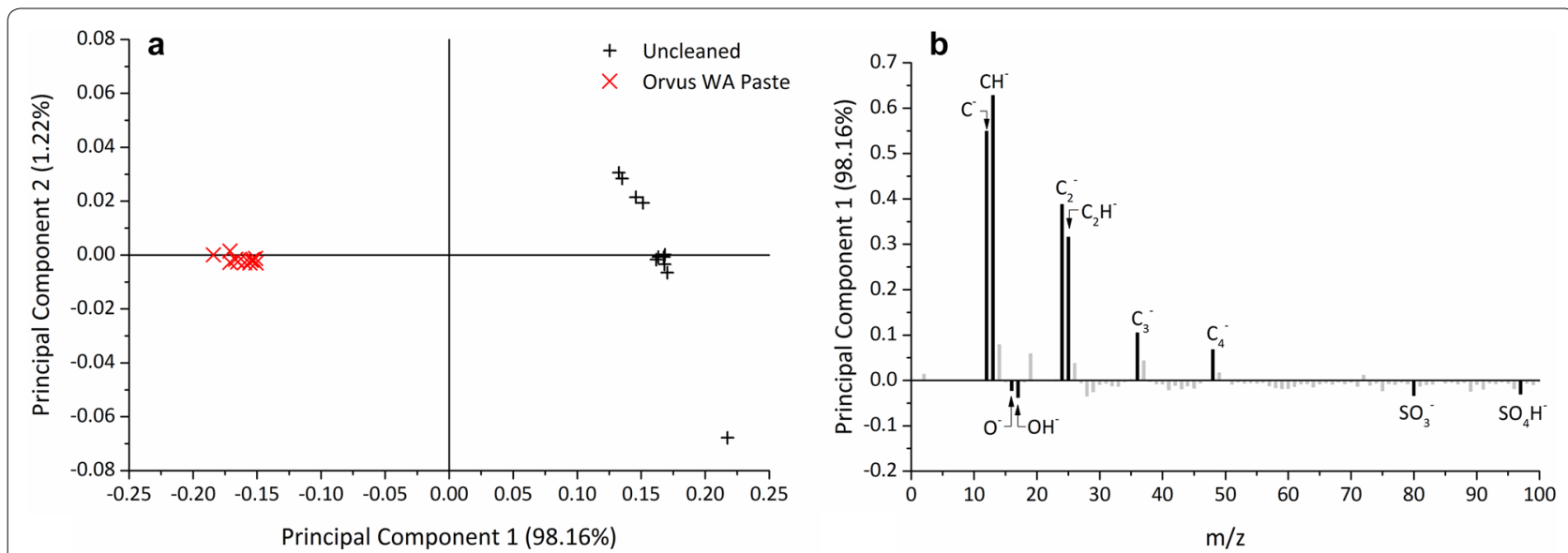

Fig. 6 PCA $\mathbf{a}$ scores and $\mathbf{b}$ loadings plots for the negative polarity ToF-SIMS spectra from the substrates cleaned with the anionic surfactant (Orvus WA Paste)
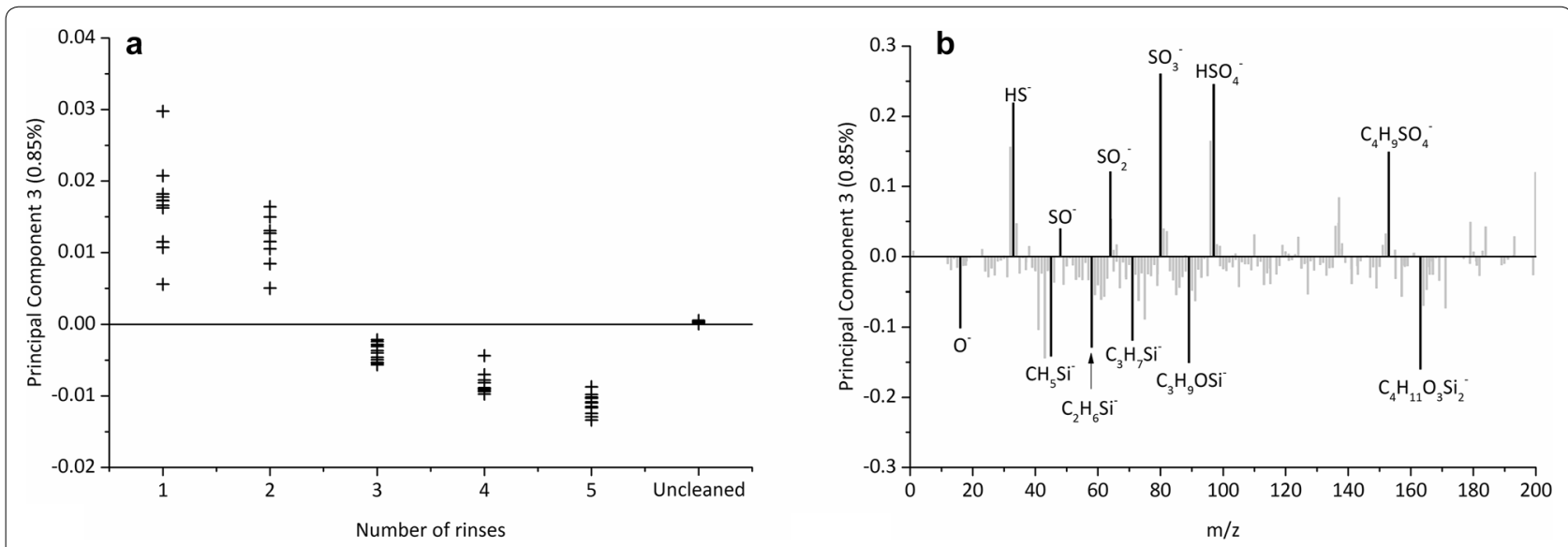

Fig. 7 PCA a scores and $\mathbf{b}$ loadings plots for the negative polarity ToF-SIMS spectra from substrates cleaned with the anionic surfactant and rinsed
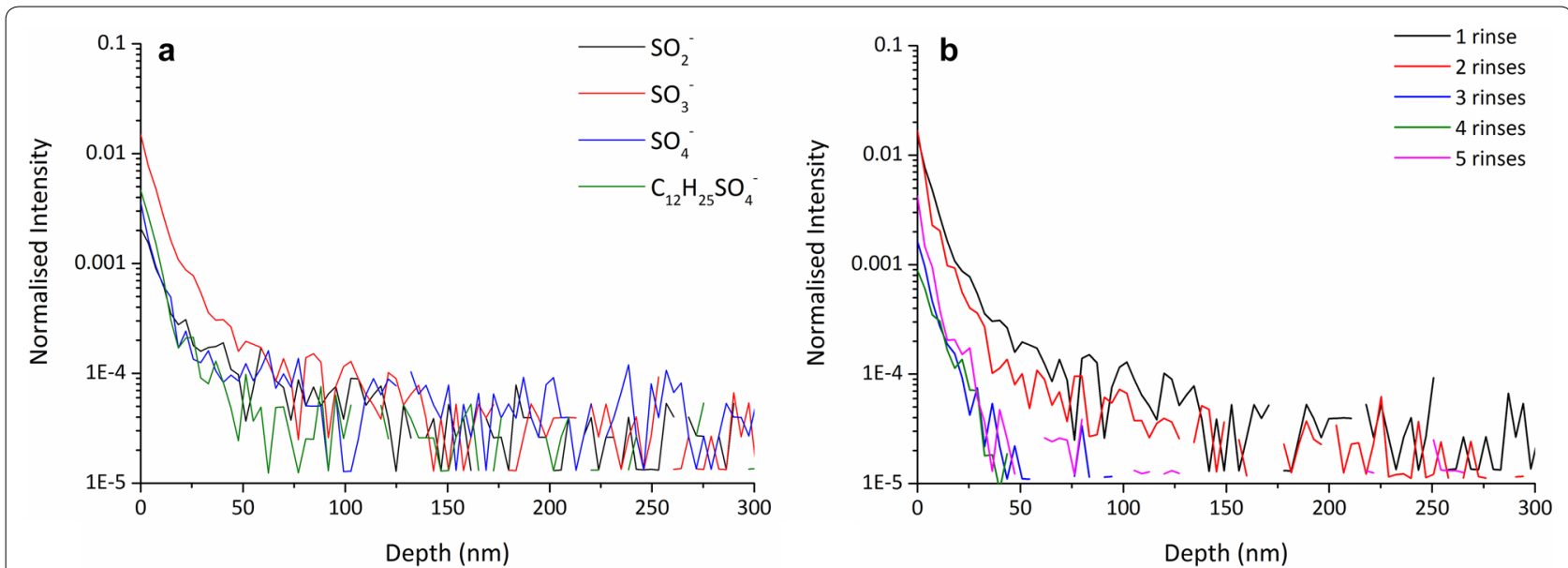

Fig. 8 Negative polarity ToF-SIMS depth profiles for the polystyrene substrate cleaned with the anionic surfactant and $\mathbf{a}$ rinsed once and $\mathbf{b}$ rinsed multiple times $\left(\mathrm{SO}_{3}{ }^{-}\right.$fragment shown) 


\section{Discussion}

Findings from this work indicate that all cleaning treatments introduce scratches to the polystyrene surface, in agreement with previous work [5]. SEM and AFM inspection of the surface after cleaning revealed these scratches have a typical width of around $500 \mathrm{~nm}$ and a peak-to-valley height of around $20 \mathrm{~nm}$, indicating they are relatively narrow, shallow and unlikely to be visible to the naked eye. Their formation on the surface appears to be random and their positioning is not regular. Indeed, the scratches on a surface may be isolated or may appear in clusters, the latter potentially increasing their visibility.

The use of microfibre cloths to clean other plastic materials has previously been explored. Castella and Moore [13] found that the repeated wiping of a dry microfibre cloth over the surface of poly (methyl methacrylate) (PMMA) resulted in the appearance of scratches. The addition of a cleaning agent has been linked to a reduction in the number of scratches $[5,13]$ and attributed to a lubrication effect. However, this could not be verified in this work due to the random nature of the scratches observed.

It is reasonable to suggest that the appearance of scratches is significantly affected by the hardness of the plastic and the pressure exerted during the cleaning process. It would therefore be of interest to explore the effect of these variables on their formation and topography. The structure of the microfibre cloth is also of interest; the cloth used in this work had a flat, close weave and it is possible that the use of a cloth with a longer nap would affect the formation of scratches.

Examination of the microfibre cloth prior to cleaning revealed the presence of particles adhered to the individual fibres, some of which had a typical diameter of $200 \mathrm{~nm}$ or less. It is suggested the scratches may be formed by the passage of these particles across the surface or are formed as a result of dust present on the surface prior to cleaning. A combination of the two processes is most likely. It is therefore thought the application method is more detrimental to the surface than the cleaning agent used. A cleaning methodology that does not involve a translational cleaning motion would be expected to reduce the extent of scratching to the surface.

Analysis of changes in the chemical composition of the surface was achieved using PCA analysis of ToF-SIMS data. The substrates cleaned with anionic and non-ionic surfactants were of particular interest as the application of surfactants is commonly followed by clearing steps to remove residue. PCA analysis of the data revealed both substrates cleaned with surfactants could be characterised by residual surfactant. Repeated rinsing of the substrate cleaned with the anionic surfactant resulted in the substrate being increasingly characterised by fragments attributed to PDMS. This is a lubricant found in the laboratory environment, including in wash bottles and on protective gloves [14]. In contrast, substrates undergoing fewer rinsing steps were characterised by fragments corresponding to residual surfactant. There are three possible explanations for this: surfactant is being removed with repeated rinsing, there is an increase in contamination, or a combination of these is occurring. The latter scenario is the most likely, with repeat rinsing resulting in a reduction in surfactant residue but also an increase in contamination from the cleaning process.

Depth profiles of the substrate cleaned with the anionic surfactant revealed the presence of a thin layer of residual surfactant. Further examination of cleaned substrates indicated that repeat rinsing did not remove the residue entirely and a monolayer of surfactant is still present on the surface. Repeat rinsing may therefore introduce scratches and contamination to the surface while not resulting in the entire removal of the surfactant.

\section{Conclusions}

Findings from this work give valuable information about the physical and chemical changes occurring to the surface of polystyrene substrates as a result of the application of different cleaning agents. While surface damage is not visible to the naked eye, inspection of the surface with SEM and AFM reveals the presence of scratches attributed to the mechanical action of the microfibre cloth over the substrate. These are thought to be due to the passage of small particles over the surface, which may result from dust particulates or particles already present on the microfibre cloth fibres. Scratches were present on all substrates, regardless of the cleaning agent under investigation. This indicates surface damage may be greater than is apparent with the naked eye or under low magnification techniques and that cleaning can introduce potential areas of weakness to the surface. The hardness of any particulate contamination is also likely to affect the formation of scratches and therefore the minimum pressure that is effective in removing the contamination is required. Significant scratching may occur at higher pressures.

Principal component analysis of the ToF-SIMS data from the substrates cleaned with both surfactants reveals the presence of fragments corresponding to residual surfactant. Depth profiles of the surface region indicate this residue forms a thin layer on the surface of the polystyrene. Repeated rinsing of the substrates is thought to result in a reduction in surfactant residue accompanied by an increase in contamination from the cleaning process. The efficacy of repeated clearing steps should therefore be considered, given a monolayer of surfactant is still present on the surface after multiple rinses, and 
that rinsing is accompanied by the potential to introduce damage and contamination to the surface. However, it is also possible that the presence of residual surfactant acts to passivate the surface, reducing further contamination.

\section{Abbreviations}

AFM: atomic force microscopy; ATR-FTIR: attenuated total reflectance Fourier transform infra-red spectroscopy; FEG-SEM: field emission gun-scanning electron microscopy; PC1: principal component 1; PCA: principal component analysis; PDMS: polydimethylsiloxane; PV: peak-to-valley; SEM: scanning electron microscopy; SIMS: secondary ion mass spectrometry; SLS: sodium lauryl sulphate; ToF-SIMS: time-of-flight secondary ion mass spectrometry; V\&A: Victoria and Albert Museum.

\section{Authors' contributions}

ALF performed data collection, analysis and drafted the manuscript. DSM, BK and BP supervised the project, assisted the experimental design and reviewed the manuscript. All authors read and approved the final manuscript.

\section{Author details}

1 Department of Materials, Imperial College London, Exhibition Road, London SW7 2AZ, UK. ${ }^{2}$ Conservation Department, Victoria and Albert Museum, South Kensington, London SW7 2RL, UK. ${ }^{3}$ School of Natural Sciences and Mathematics, Department of Chemistry and Biochemistry, University of Texas at Dallas, 800 W. Campbell Rd, Richardson, TX 75080-3021, USA.

\section{Acknowledgements}

Not applicable.

\section{Competing interests}

The authors declare that they have no competing interests.

\section{Availability of data and materials}

The datasets supporting the conclusions of this article are included within the article.

\section{Funding}

The authors gratefully acknowledge the support of the Arts and Humanities Research Council (AHRC) in funding this work through their Collaborative Doctoral Award scheme.

\section{Publisher's Note}

Springer Nature remains neutral with regard to jurisdictional claims in published maps and institutional affiliations.
Received: 28 October 2016 Accepted: 25 May 2017

Published online: 20 July 2017

\section{References}

1. Then E, Oakley V. A survey of plastic objects at the Victoria and Albert Museum. V\&A Conserv J. 1993;06:11-4.

2. Ward C, Shashoua Y. Conservation survey of objects containing plastics and rubber in the department of ethnography. Report no. 94/24/0/9. Department of Conservation, British Museum, 1994.

3. Morgan J. A survey of plastics in historical collections. Plastics Historical Society and The Conservation Unit of Museums and Galleries Commission; 1994.

4. Shashoua Y. Conservation of plastics: materials science, degradation and preservation. Amsterdam: Elsevier; 2008

5. Balcar N. Studies in cleaning plastics. In: Lavédrine B, Fournier A, Martin G, editors. Preservation of plastic artefacts in museum collections (POPART). Paris: Comité des travaux historiques et scientifiques (CTHS); 2012. p. 225-69.

6. Shashoua Y, et al. Wiping away the dirt-a safe option for plastics? In: ICOM-CC Lisbon 2011: preprints, 19-23 September 2011. Lisbon, Portugal; 2011

7. Morales Muñoz C. Surface modification of plasticized PVC by dry cleaning methods: consequences for artworks. Appl Surf Sci. 2010;256(11):3567-72

8. Morales Muñoz C, et al. A model approach for finding cleaning solutions for plasticized poly(vinyl chloride) surfaces of collections objects. J Am Inst Conserv. 2014:53(4):236-51.

9. Dowsett M, Adriaens A. The role of SIMS in cultural heritage studies. Nucl Instr Meth Phys Res B Beam Interact Mater At. 2004:226(1-2):38-52.

10. Abel M-L, Coppitters C. Conservation of polymers: a view to the future. Surf Interface Anal. 2008:40(3-4):445-9.

11. Briggs D. Surface analysis of polymers by XPS and static SIMS. Cambridge: Cambridge University Press; 1998.

12. Fearn S. An introduction to time-of-flight secondary ion mass spectrometry (ToF-SIMS) and its application to materials science. San Rafael: Morgan \& Claypool; 2015

13. Casella $\mathrm{L}$, Moore $C$. Research on methods of cleaning face-mounted photographs. Top Photogr Preserv. 2009;13:200-8.

14. Morinville W, Krasinski C. Secondary ion mass spectrometry analysis of wafer contamination resulting from gloved hands. 2006 IEEE workshop on microelectronics and electron devices, 14 April 2006. Boise, Idaho; 2006. p. 35-36.

\section{Submit your manuscript to a SpringerOpen ${ }^{\circ}$ journal and benefit from:}

- Convenient online submission

- Rigorous peer review

- Immediate publication on acceptance

- Open access: articles freely available online

High visibility within the field

- Retaining the copyright to your article

Submit your next manuscript at springeropen.com 